\title{
Mordida cruzada posterior: uma classificação mais didática
}

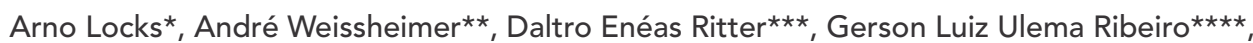 \\ Luciane Macedo de Menezes ${ }^{\star \star \star \star}$, Carla D'Agostini Derech ${ }^{\star \star \star \star}$, Roberto Rocha ${ }^{\star \star \star \star}$
}

\begin{abstract}
Resumo
O objetivo deste trabalho é apresentar uma nova classificação de mordida cruzada posterior, sendo esta mais didática e de fácil entendimento, diferindo das demais em sua nomenclatura, preservando, no entanto, os princípios fundamentais que regem a Ortodontia. Essa classificação torna o processo de diagnóstico da mordida cruzada posterior sistematizado, tornando-o mais preciso, auxiliando o clínico na elaboração de um plano de tratamento adequado e, como conseqüência, levando a um prognóstico mais favorável dessa má oclusão.
\end{abstract}

Palavras-chave: Má oclusão. Mordida cruzada posterior. Nova classificação.

\section{INTRODUÇÃO}

No que se refere à classificação das mordidas cruzadas posteriores, a literatura compulsada apresenta-se diversificada e sofrendo diversas modificações de acordo com a experiência de cada autor, permitindo, desta maneira, que haja uma certa dificuldade na compreensão, diagnóstico e tratamento destas más oclusões.

O objetivo principal deste trabalho é apresentar uma nova classificação de mordida cruzada posterior, sendo esta de mais fácil entendimento, diferindo das demais em sua nomenclatura, preservando, no entanto, os princípios fundamentais que regem a Ortodontia, mas devido à sua metodologia, induz com facilidade a um plano de tratamento adequado.

\section{REVISÃO DE LITERATURA}

Entende-se por mordida cruzada posterior a relação anormal, vestibular ou lingual de um ou mais dentes da maxila, com um ou mais dentes da mandíbula, quando os arcos dentários estão em relação cêntrica, podendo ser uni ou bilateral ${ }^{8}$.

Moyers ${ }^{19}$ classificou as mordidas cruzadas, com base em sua etiologia, em: dentária - quando resultante de um sistema imperfeito de erupção, onde um ou mais dentes posteriores irrompem numa relação de mordida cruzada, mas não afetando o tamanho ou a forma do osso basal; muscular - quando ocorre uma adaptação funcional às interferências dentárias, sendo que os dentes não estão inclinados dentro do processo alveolar, porém, apresentando um deslocamento da mandíbula e um desvio da linha média; e óssea - que ocorre em conseqüência de uma discrepância na estrutura da mandíbula ou maxila, conduzindo a uma alteração na largura dos arcos. Esta má oclusão pode se apresentar uni ou bilateralmente, bastando, para o diagnóstico definitivo, posicionar a mandibula de tal maneira que haja coincidência das linhas médias inferior e su-

Mestre em Ortodontia pela UFRJ. Doutor em Ortodontia pela UNESP. Pós-Doutorado em Ortodontia pela Universidade de Aarhus-Dinamarca.

* Especialista em Ortodontia pela UFSC. Mestrando em Ortodontia pela PUC-RS.

*** Mestre em Ortodontia pela UERJ. Doutor em Ortodontia pela UNESP.

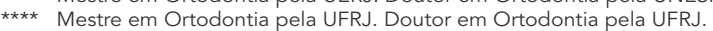


perior, uma vez que vários pacientes com mordida cruzada unilateral poderiam ser portadores de uma constrição bilateral do arco.

Cohen ${ }^{5}$ considerou as mordidas cruzadas posteriores como sendo de origem ambiental ou funcional, esquelética e dentária. As de origem ambiental ou funcional constituem a maioria das mordidas cruzadas posteriores encontradas na dentadura decídua, sendo o fator etiológico um contato prematuro nos dentes decíduos. As más oclusões de origem esquelética, seriam resultantes de um desenvolvimento desarmonioso, na maxila ou mandíbula, e que se manifestaria em um desequilibrio da oclusão, anterior ou posterior, podendo ser uni ou bilateral. O grupo das mordidas cruzadas posteriores de origem dentária, ocorreria quando os molares inferiores apresentassem línguo ou lábio-versão, e os molares superiores em línguo-versão e/ou extrema lábio-versão.

McDonald e Avery ${ }^{17}$ classificaram a mordida cruzada posterior em óssea - quando a mesma era resultante de discrepância na estrutura da mandíbula ou da maxila, podendo existir uma discrepância na largura dos arcos, e uma inclinação lingual dos dentes superiores; dentária - quando a má oclusão era resultado de um sistema imperfeito de erupção dentária, apresentando um ou mais dentes em relacionamento de mordida cruzada, porém, não apresentando irregularidade alguma no osso basal; e funcional - quando a má oclusão era decorrente de um deslocamento da mandíbula para uma posição anormal, porém mais confortável para o paciente. É importante observar que na mordida cruzada funcional não ocorriam sinais de discrepância nas linhas médias superior e inferior quando a mandíbula encontrava-se em posição de repouso, porém apresentando desvio da mandíbula, no sentido da mordida cruzada, quando os dentes entravam em oclusão.

Vigorito ${ }^{26}$ classificou as mordidas cruzadas posteriores segundo suas origens, em funcionais, dentárias e esqueléticas. As de origem funcional são caracterizadas por uma tendência da mandíbula em sofrer desvios de lateralidade, como conseqüência da erupção dos caninos decíduos, que estariam numa relação de oclusão de topo (adaptação funcional). As de origem dentária são caracterizadas pela inversão da oclusão dos dentes e por não afetarem as dimensões dos arcos basais. As esqueléticas, apresentam deficiência de crescimento em largura dos ossos basais, podendo produzir atresias bilaterais da maxila, gerando como conseqüência mordida cruzada unilateral ou bilateral.

Proffit et al.22 classificou as mordidas cruzadas posteriores em: esqueléticas - quando resultantes de uma maxila estreita ou de uma mandíbula excessivamente larga; dentárias - quando a base da abóboda palatina apresenta-se normal, mas os processos dentoalveolares inclinavam-se para lingual; dentoalveolares - quando ocorria uma inclinação dos dentes e respectivos alvéolos superiores no sentido lingual, ocorrendo também uma atresia da maxila, porém não sendo observado aprofundamento da abóboda palatina e funcional, quando ocorria desvio da mandíbula em função de contatos deflexivos.

A denominada síndrome de Brodie é uma condição que pode resultar de um excesso da largura maxilar, ou de uma atresia severa do arco mandibular, ou ainda uma associação dos dois, quando os dentes superiores ocluem totalmente por vestibular em relação aos inferiores.

Quanto à etiologia das mordidas cruzadas posteriores, há diferentes fatores como prováveis causadores da referida má oclusão ${ }^{5,17,19,24,25,26}$ tais como a respiração bucal ${ }^{1,7,17,19,22,25,26}$, hábitos bucais deletérios ${ }^{1,7,16,17,21,25,26}$, perda precoce ou retenção prolongada de dentes decíduos ${ }^{15,17,25}$, migração do germe do dente permanente ${ }^{32}$, interferências oclusais $^{2,3}$, anomalias ósseas congênitas ${ }^{19,27}$, falta de espaço nos arcos (discrepância entre o tamanho do dente e o tamanho do arco ${ }^{27}$, fissuras palatinas ${ }^{5,27} \mathrm{e}$ hábitos posturais incorretos ${ }^{10}$.

A grande maioria dos casos de mordida cruzada posterior manifesta-se unilateralmente. No entanto, com a mandíbula manipulada em relação cêntrica, quase sempre se observa comprometimento de ambos os lados do arco dentário, havendo uma relação de mordida de topo bilateral, provocando 
instabilidade oclusal, levando a um desvio da mandíbula, quando então o paciente busca uma posição mais confortável.

Com a finalidade de elucidar o diagnóstico e simplificar o tratamento das mordidas cruzadas posteriores, deve-se manipular a mandíbula em relação cêntrica em qualquer idade, mas principalmente nas dentadura decídua e mista ${ }^{28}$, pois as crianças não possuem a articulação temporomandibular desenvolvida o suficiente para ter o equivalente da posição de relação cêntrica dos adultos ${ }^{22}$.

Com relação à prevalência de mordidas cruzadas posteriores, tanto na dentadura decídua como na mista, estudos sugerem uma variação entre $3,46 \%$ e $23,95 \%$, embora na maioria das pesquisas esta taxa situa-se na faixa de $8 \%$ a $16 \% 6,8,11,12,14,18,21$.

\section{NOVA CLASSIFICAÇÃO}

Segundo nosso entendimento, a classificação de mordida cruzada posterior aqui apresentada favorece a compreensão e facilita a diferenciação entre os diversos tipos da referida má oclusão, tornando seu diagnóstico mais preciso, favorecendo o profissional na elaboração de um adequado plano de tratamento e obtendo, como conseqüência, um prognóstico mais favorável.

Inicialmente, o exame clínico é realizado com o paciente ocluindo na posição de máxima intercuspidação habitual (MIH), com o objetivo de se verificar a presença de mordida cruzada posterior. Para o diagnóstico definitivo, uma vez constatada a má oclusão, proceder-se-á a manipulação da mandíbula em relação cêntrica (RC), observando, novamente, o relacionamento dentário posterior.

Em função deste relacionamento, os diferentes casos de mordida cruzada posterior são agrupados, segundo sua origem, em 4 categorias distintas, como pode ser visto no quadro 1 .

\section{MORDIDA CRUZADA FUNCIONAL Diagnóstico inicial}

O paciente, quando observado em norma fa-

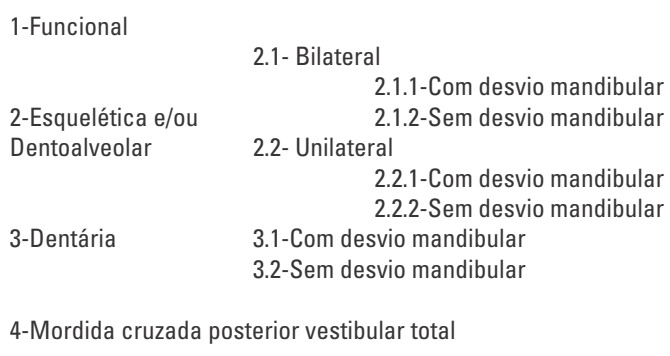

Quadro 1 - Classificação de mordida cruzada posterior.

cial frontal, apresenta assimetria facial por desvio em lateralidade da mandíbula (Fig. 1).

Ao exame intrabucal em MIH observa-se a presença de mordida cruzada unilateral e desvio de linha média inferior para o lado da mordida cruzada (Fig. 2).

Devido à memória muscular, geralmente ocorre assimetria mandibular mesmo quando a mandíbula se encontra em posição de repouso.

\section{Diagnóstico definitivo}

Para se obter o diagnóstico definitivo, a mandíbula é manipulada em relação cêntrica, a fim de se observar o relacionamento dentário posterior.

O paciente apresenta mordida cruzada funcional quando, em relação cêntrica, não ocorre mais a presença de mordida cruzada posterior, observando-se contato prematuro de algum elemento dentário, geralmente em caninos decíduos (Fig. 3). Nos casos de mordida cruzada funcional não ocorre real atresia maxilar (Fig. 4), mas somente uma acomodação mandibular para a melhor intercuspidação dentária, com o objetivo de desviar dos contatos prematuros. Geralmente a mordida cruzada funcional ocorre muito precocemente, na dentadura decídua. Esta mordida cruzada, quando não tratada neste período, tem tendência a evoluir para uma mordida cruzada verdadeira, pois a mesma pode ter sua etiologia em algum hábito, como respiração bucal, sucção de dedo ou chupeta.

O tratamento indicado é o desgaste seletivo em dentes decíduos, para eliminação de interferências oclusais. 


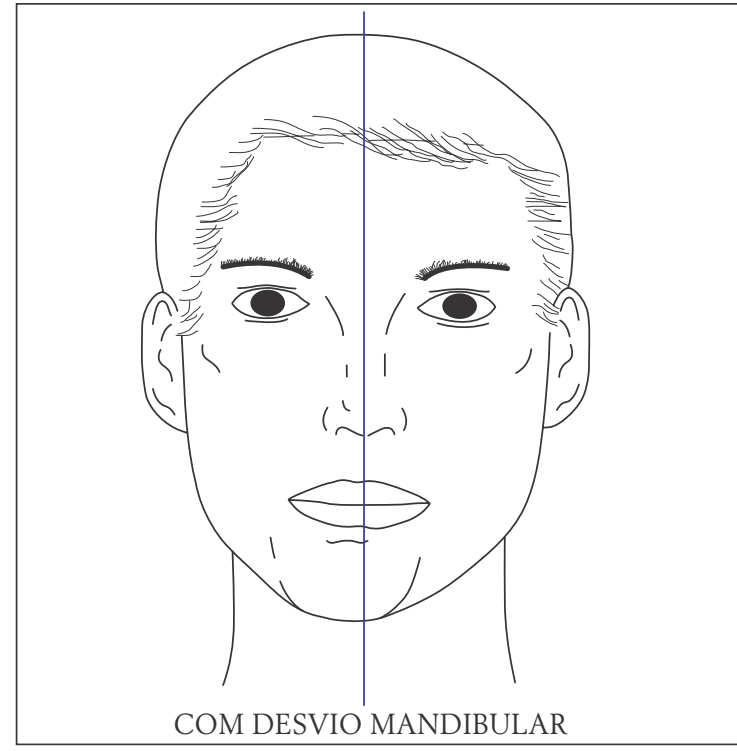

FIGURA 1 - Desvio mandibular em MIH.

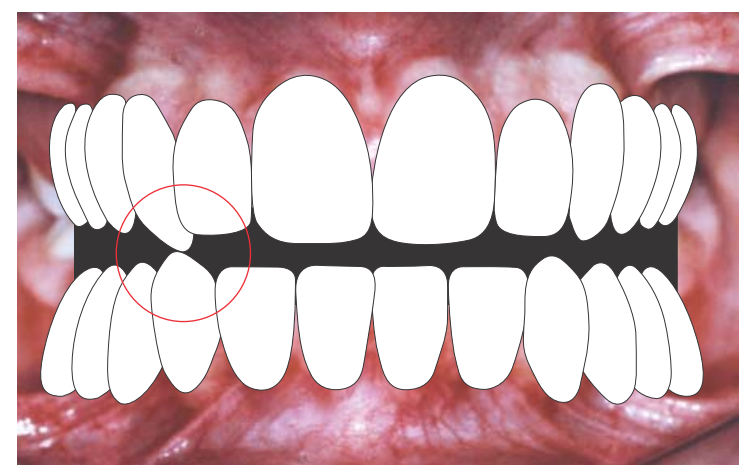

FIGURA 3 - Coincidência das linhas médias dentárias e ausência de mordida cruzada posterior em RC (mordida cruzada funcional, causada por contato prematuro).

\section{MORDIDA CRUZADA ESQUELÉTICA OU DENTOALVEOLAR POSTERIOR BILATERAL COM DESVIO DE MANDÍBULA Diagnóstico inicial}

Ao se observar o paciente em norma facial frontal, constata-se assimetria facial por desvio em lateralidade da mandíbula, exatamente igual aos casos de mordida cruzada funcional (Fig. 5).

Ao exame intrabucal em $\mathrm{MIH}$, observa-se a presença de mordida cruzada unilateral e desvio da linha média inferior para o lado da mordida

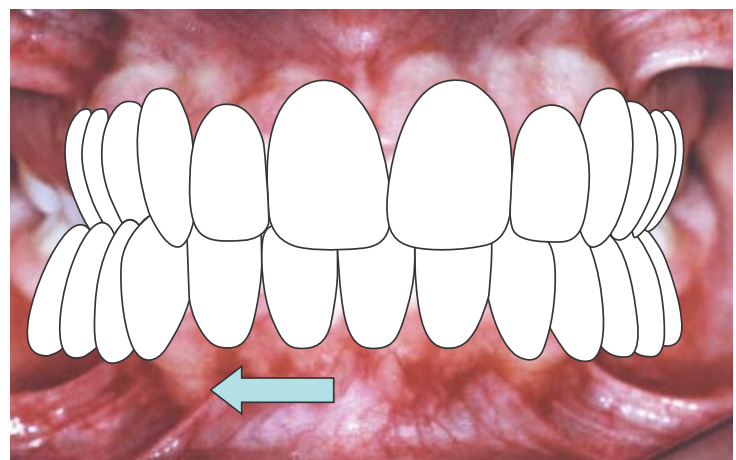

FIGURA 2 - Desvio da linha média inferior por desvio mandibular (MIH).

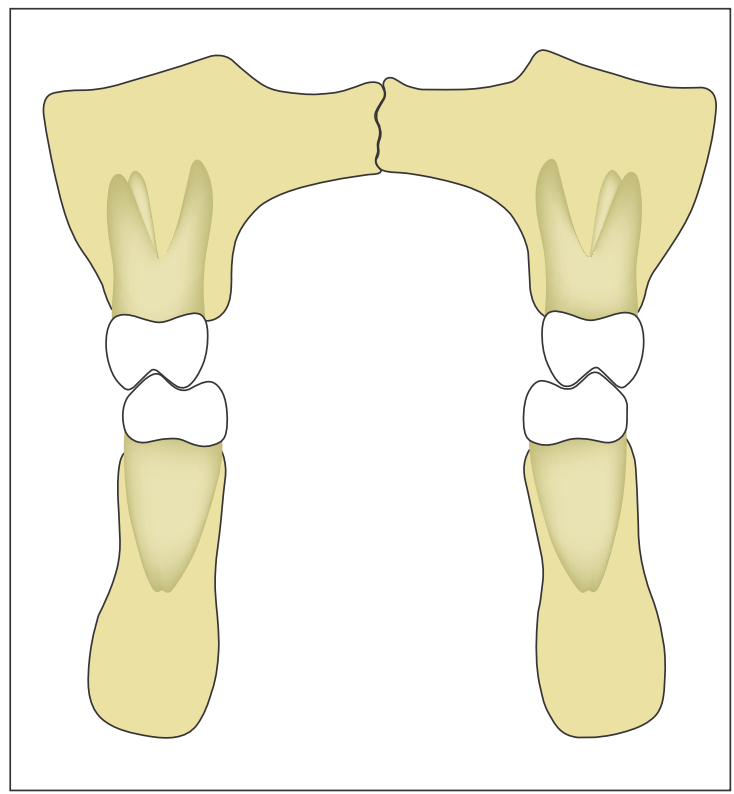

FIGURA 4 - Corte transversal em RC mostrando que tanto as bases ósseas quanto as inclinações dos dentes posteriores estão normais.

cruzada, semelhante ao observado na mordida cruzada funcional (Fig. 6).

\section{Diagnóstico definitivo}

Ao se manipular a mandíbula para posição de RC, observa-se uma relação posterior bilateral de topo-a-topo, ou seja, contato das cúspides vestibulares dos dentes superiores com as cúspides vestibulares dos dentes inferiores, demonstrando uma atresia maxilar (Fig. 7) ou , mais raramente, sobreexpansão mandibular. Como esta relação de topo- 


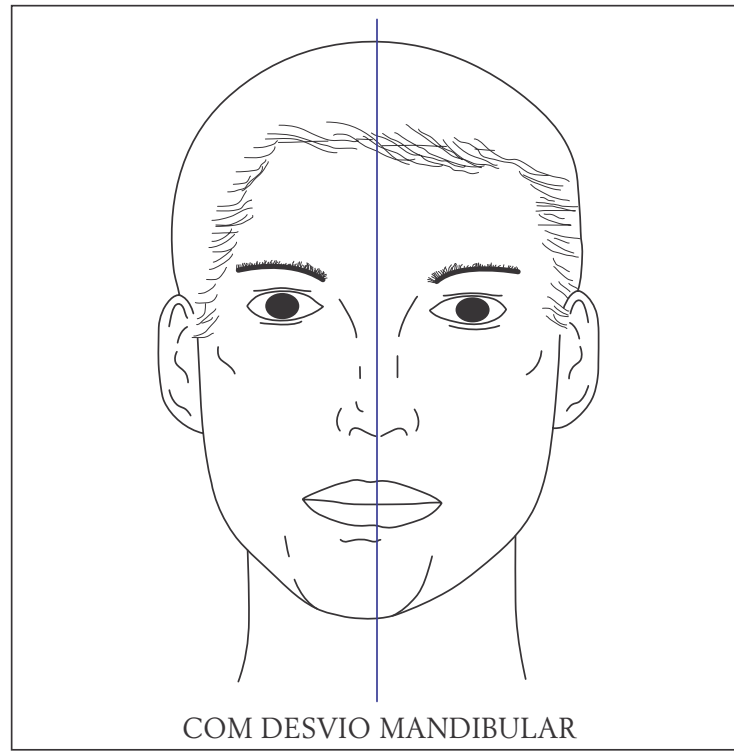

FIGURA 5 - Face assimétrica devida ao desvio mandibular, em MIH.

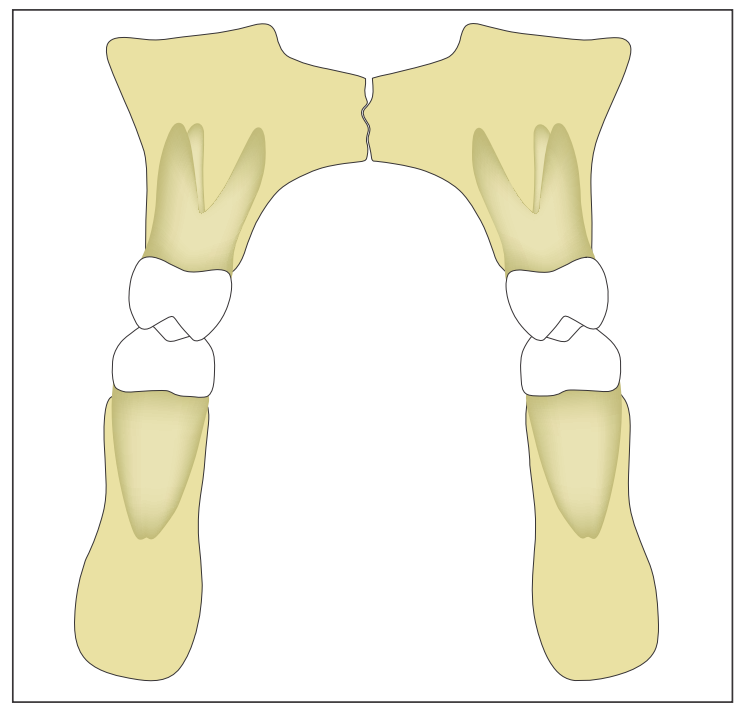

FIGURA 7 - Em RC, observa-se relação posterior de topo, devido à deficiência maxilar bilateral.

a-topo é muito desconfortável, o paciente desvia a mandíbula para um dos lados, parecendo então se tratar de mordida cruzada unilateral.

Portanto, o diagnóstico em RC indica a necessidade de expansão simétrica da maxila, pois o problema é bilateral e não unilateral.

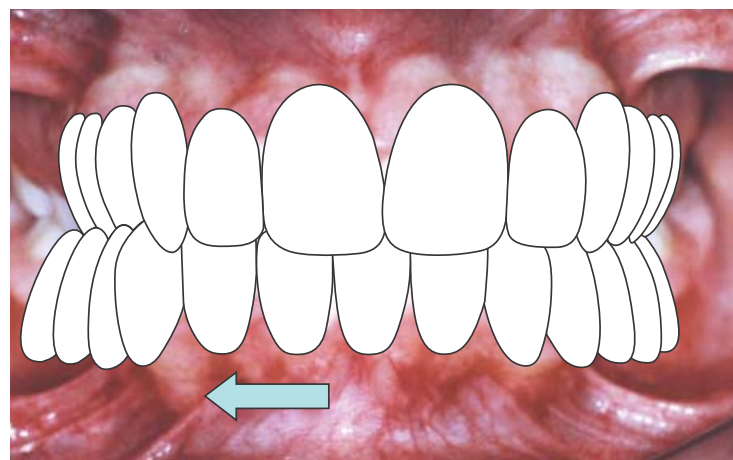

FIGURA 6 - Em MIH, há um desvio da linha média inferior para a direita e mordida cruzada unilateral no mesmo lado.

\section{MORDIDA CRUZADA ESQUELÉTICA OU DENTOALVEOLAR POSTERIOR BILATERAL SEM DESVIO MANDIBULAR Diagnóstico inicial}

Ao se observar o paciente em norma facial frontal, o mesmo não apresenta assimetria evidente, pois não há desvio de mandíbula (Fig. 8).

Entretanto, intrabucalmente em MIH, é verificada a presença de mordida cruzada posterior bilateral caracterizada por atresia maxilar acentuada, pois as cúspides vestibulares dos dentes superiores ocluem no sulco principal dos seus respectivos antagonistas. É observada coincidência das linhas médias (Fig. 9), exceção feita para os casos clínicos onde está presente um desvio de origem dentária.

\section{Diagnóstico definitivo}

Conclui-se que o paciente é portador de uma mordida cruzada posterior esquelética bilateral sem desvio de mandíbula quando, após a manipulação em relação cêntrica, constata-se o mesmo relacionamento dentário posterior verificado em MIH (Fig. 10). Os casos de mordida cruzada esquelética posterior bilateral possuem, geralmente, maxila atrésica e/ou inclinação vestibular dos dentes superiores posteriores bilateralmente (Fig. 11).

Neste caso, diferentemente da mordida cruzada posterior bilateral com desvio mandibular (em que a oclusão em topo das cúspides vestibulares dos dentes posteriores promove desvio mandibular), como a atresia de maxila é maior, as cúspides 


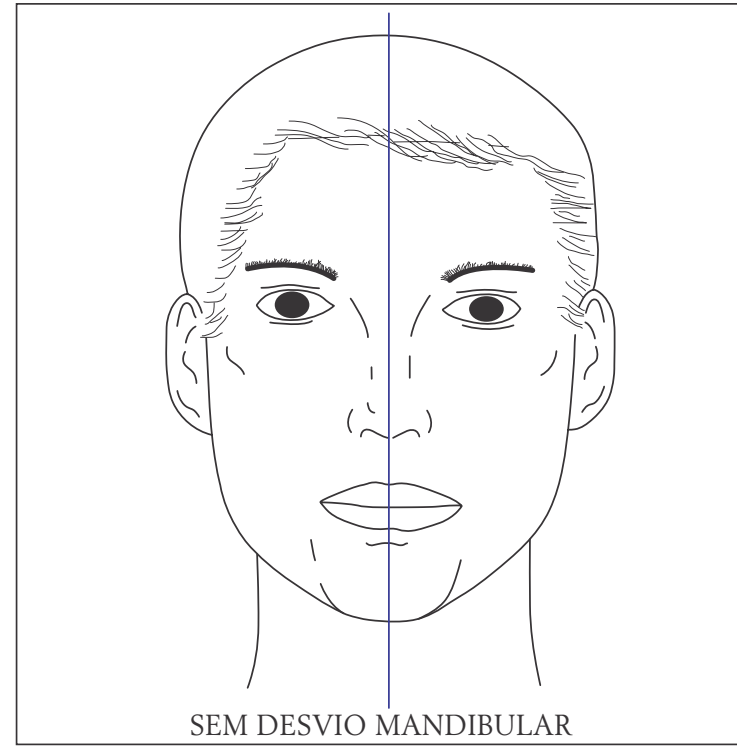

FIGURA 8 - Ausência de desvio mandibular em MIH.

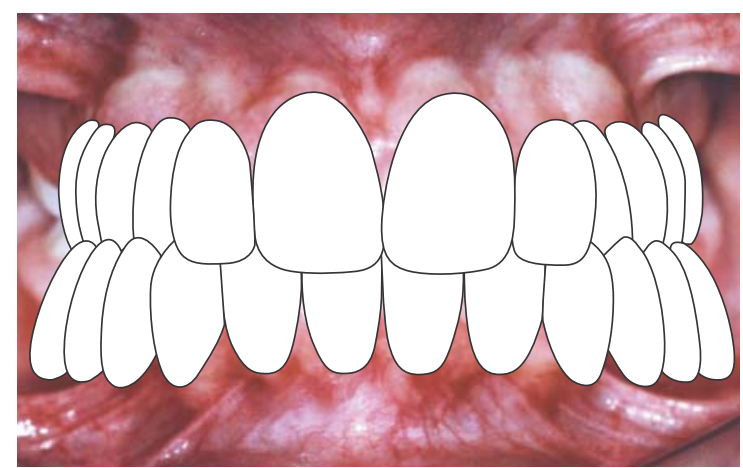

FIGURA 10 - Em RC, as linhas médias dentárias permanecem coincidentes e ainda há uma mordida cruzada posterior esquelética bilateral.

vestibulares superiores ocluem no sulco principal dos dentes inferiores, resultando numa oclusão estável e sem desvio mandibular.

Desta forma, há necessidade de expansão simétrica da maxila de uma maneira mais acentuada, pois a atresia é importante.

\section{MORDIDA CRUZADA ESOUELÉTICA OU DENTOALVEOLAR POSTERIOR UNILATERAL COM DESVIO MANDIBULAR \\ Diagnóstico inicial}

A exemplo da mordida cruzada funcional e

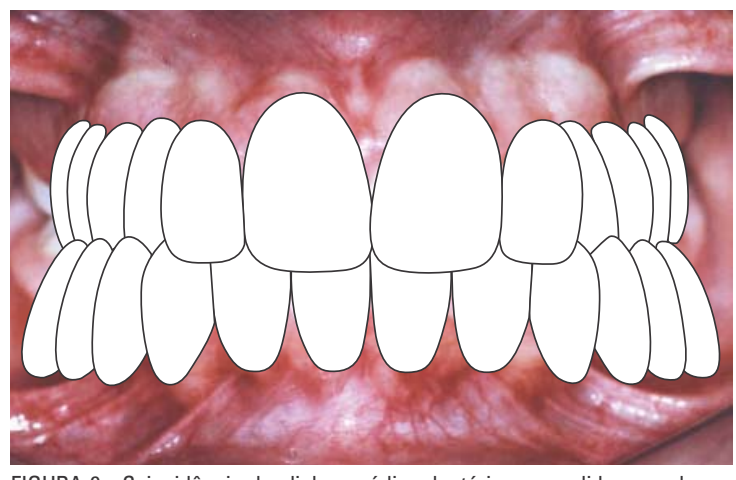

FIGURA 9 - Coincidência das linhas médias dentárias e mordida cruzada esquelética posterior bilateral quando em $\mathrm{MIH}$.

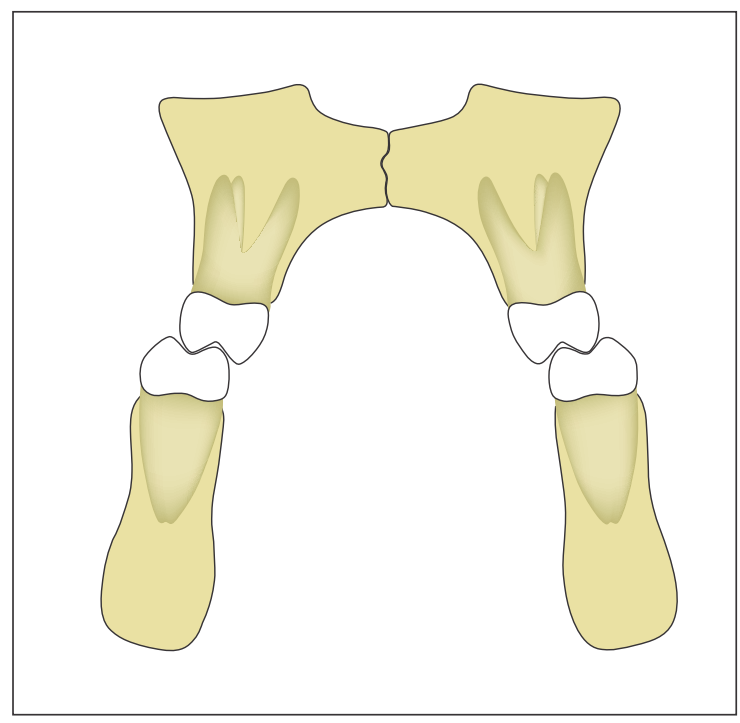

FIGURA 11 - Corte transversal. Em RC permanece a mordida cruzada posterior, pois existe uma atresia maxilar bilateral acentuada, associada com inclinação vestibular dos dentes posteriores superiores.

mordida cruzada posterior bilateral com desvio mandibular, no exame facial em norma frontal o paciente apresenta assimetria facial pelo desvio em lateralidade da mandíbula (Fig. 12). Durante o exame intrabucal em MIH é observada mordida cruzada posterior unilateral com desvio de linha média inferior para o lado do cruzamento (Fig. 13).

\section{Diagnóstico definitivo}

No diagnóstico definitivo desta má oclusão, se ao ser realizada a manipulação da mandíbula em RC for constatada a permanência da mordida cruzada unilateral, verifica-se uma mordida cru- 


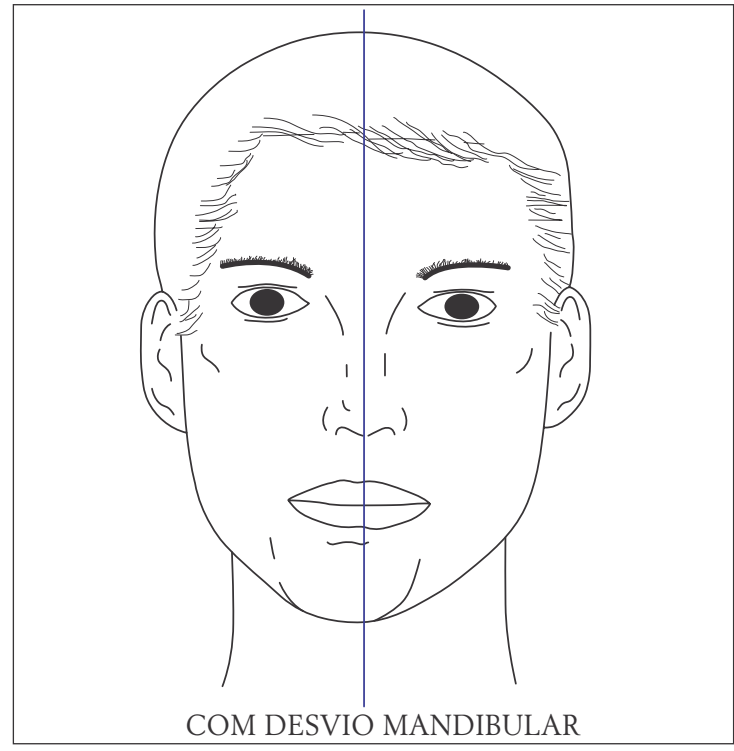

FIGURA 12 - Presença de desvio mandibular em MIH.

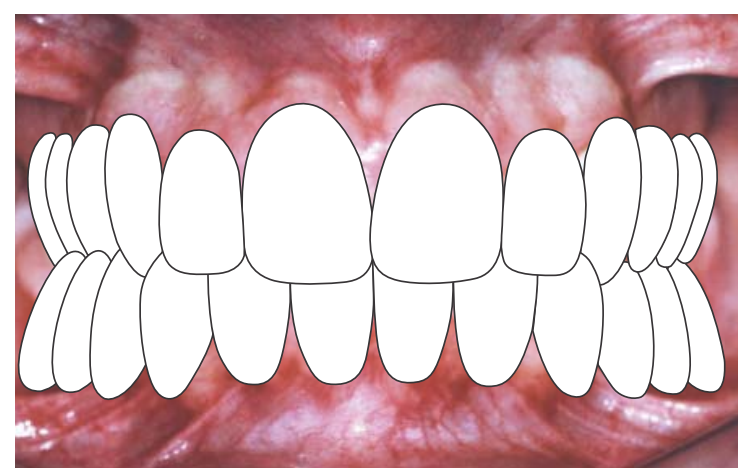

FIGURA 14 - Em RC, há ausência de assimetria e presença de mordida cruzada unilateral.

zada posterior esquelética unilateral com desvio de mandíbula (Fig. 14), pois o paciente desvia a mandíbula em MIH, devido a contatos prematuros desconfortáveis, quando em oclusão.

Ao se analisar o arco maxilar numa visão posterior, constata-se a atresia do lado da mordida cruza$\mathrm{da}$, demonstrando um arco assimétrico, indicando a necessidade de expansão assimétrica, com mais ação do lado da mordida cruzada (Fig. 15). Já no arco inferior, geralmente é observada uma verticalização dos dentes do lado da mordida cruzada, como conseqüência da oclusão invertida deste lado.

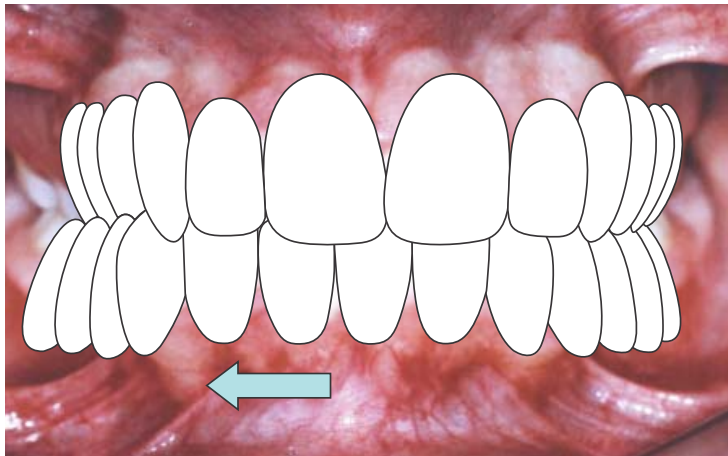

FIGURA 13 - Em MIH, há desvio da linha média dentária inferior e mordida cruzada posterior unilateral.

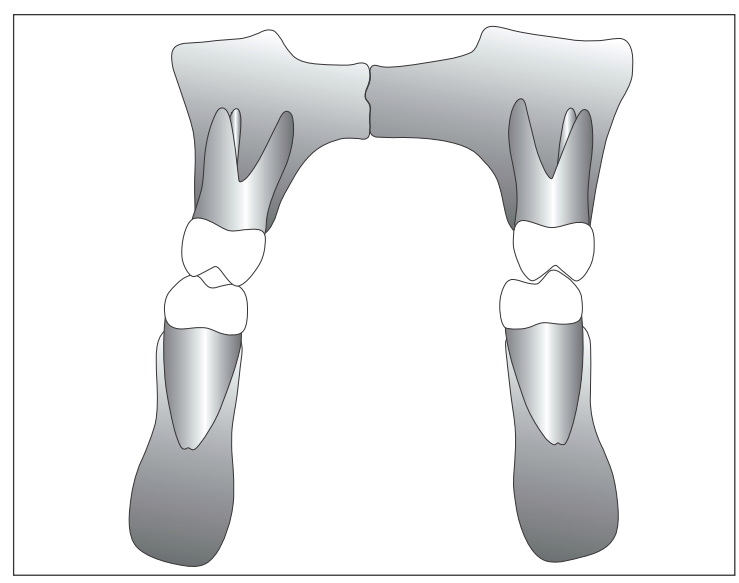

FIGURA 15 - Corte transversal em RC, evidenciando a atresia maxilar unilateral.

\section{MORDIDA CRUZADA ESOUELÉTICA OU DENTOALVEOLAR POSTERIOR UNILATERAL SEM DESVIO MANDIBULAR Diagnóstico inicial}

Durante o exame facial em norma frontal, não se verifica assimetria facial, pois a mandíbula não apresenta desvio ou assimetria (Fig. 16). Intrabucalmente, em MIH, o paciente apresenta coincidência de linhas médias e presença de mordida cruzada unilateral (Fig. 17), com as cúspides vestibulares superiores ocluindo no sulco principal dos dentes inferiores. 


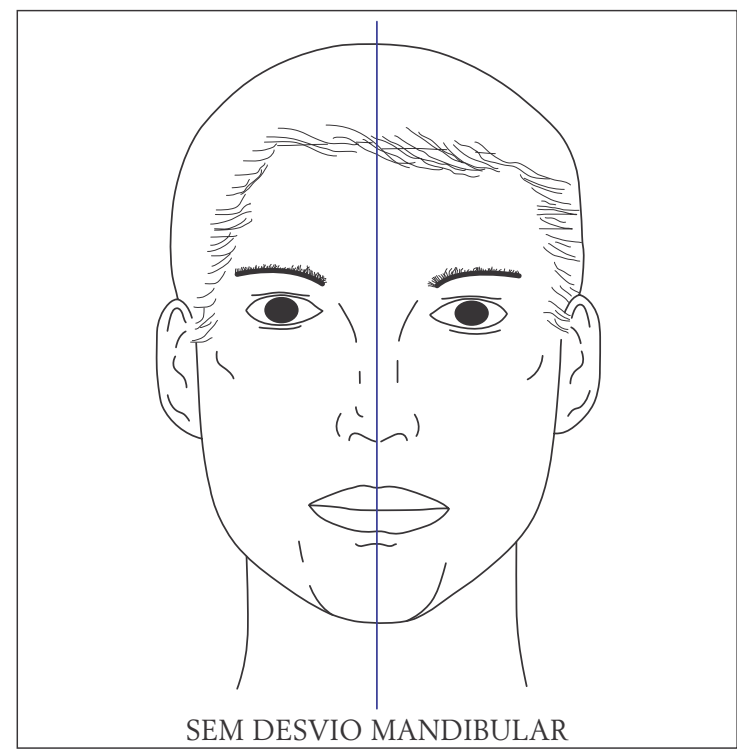

FIGURA 16 - Face simétrica e sem desvio, em MIH.

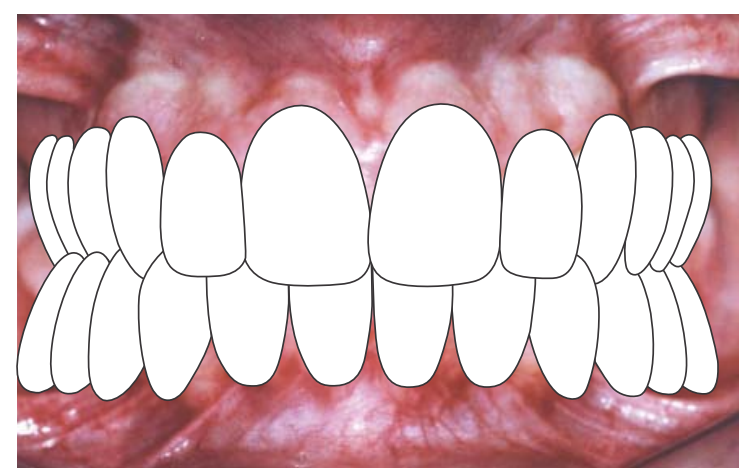

FIGURA 18 - Em RC observa-se também coincidência das linhas médias e mordida cruzada unilateral.

\section{Diagnóstico definitivo}

Com a finalidade de se diagnosticar definitivamente a referida má oclusão, a mandíbula deve ser manipulada em RC, a fim de se verificar o padrão oclusal. Será, então, classificada como mordida cruzada posterior esquelética unilateral sem desvio de mandíbula quando o referido padrão de oclusão, já constatado em $\mathrm{MIH}$, for novamente observado em RC (Fig. 18).

Quando realizado o exame do arco superior, este apresenta atresia no lado da mordida cruzada, enquanto, geralmente, no arco inferior ocorre uma

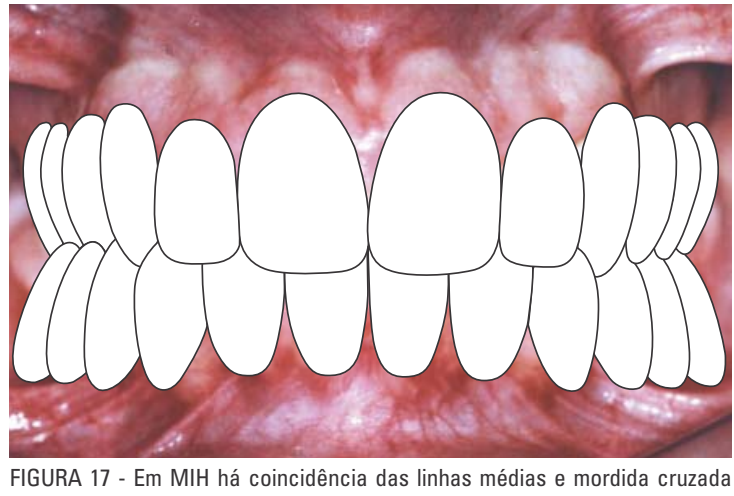
unilateral.

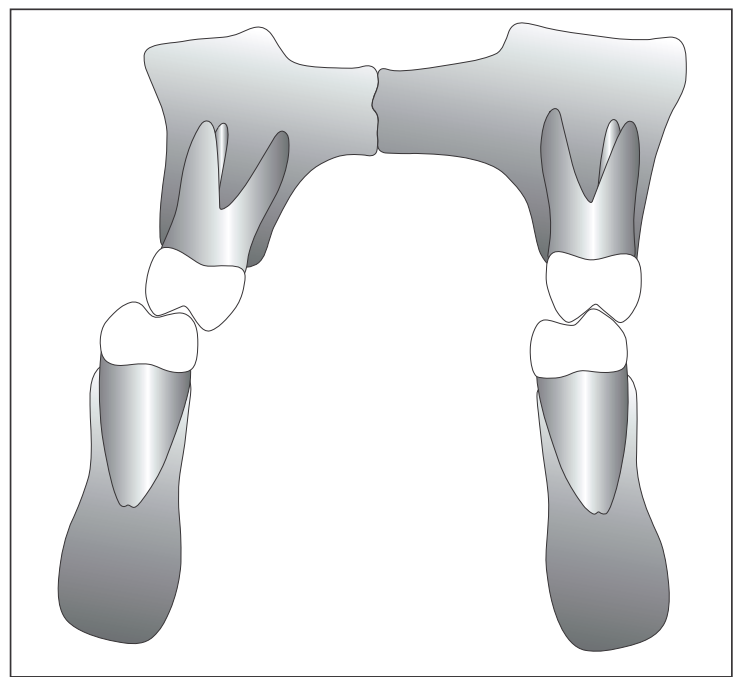

FIGURA 19 - Corte transversal em RC evidenciando uma atresia maxilar unilateral causando mordida cruzada unilateral.

verticalização dos dentes do lado do cruzamento da mordida (Fig. 19).

\section{MORDIDA CRUZADA POSTERIOR DENTÁRIA COM DESVIO MANDIBULAR \\ Diagnóstico inicial}

Durante o exame facial em norma frontal é observada assimetria facial por desvio mandibular (Fig. 20). Em MIH, o paciente apresenta um ou dois elementos dentários posteriores com assimetria em relação aos outros dentes e em mordida cruzada com seu antagonista. A presença de con- 


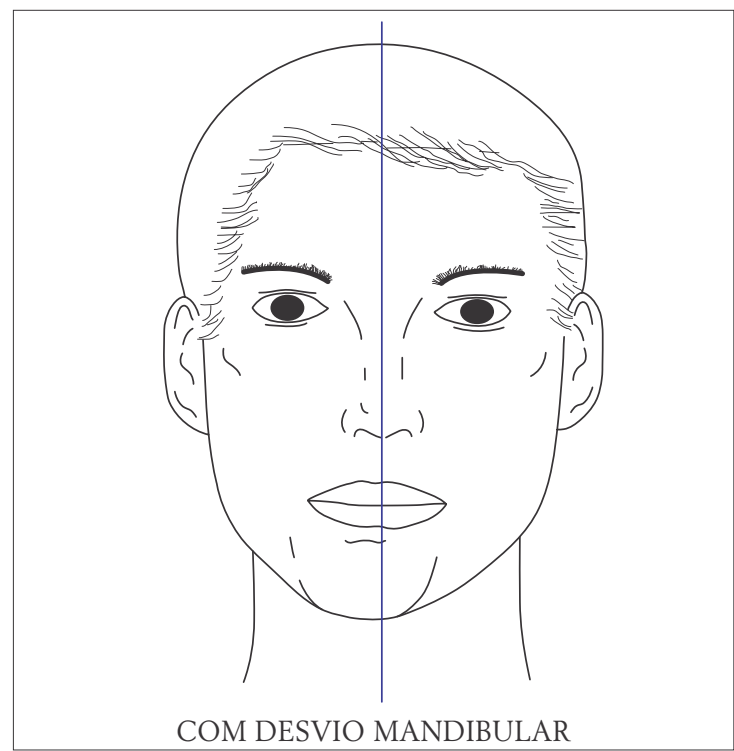

FIGURA 20 - Desvio mandibular MIH.

tatos prematuros faz com que a mandíbula seja desviada para um dos lados, na tentativa de um relacionamento oclusal mais estável, portanto há desvio de linha média inferior para o lado do cruzamento (Fig. 21). Os arcos dentários apresentamse normais, não sendo observada nenhuma atresia esquelética dos mesmos (Fig. 22).

\section{Diagnóstico definitivo}

Conclui-se que o paciente é portador de uma mordida cruzada posterior dentária com desvio mandibular quando, em RC, observa-se a presença de um ou dois elementos dentários em mordida cruzada com os seus antagonistas, devido à inclinações axiais errôneas, sem componente esquelético (Fig. 23, 24), indicando somente correção destes dentes, posicionando-os corretamente em suas bases alveolares.

\section{MORDIDA CRUZADA POSTERIOR DENTÁRIA SEM DESVIO MANDIBULAR Diagnóstico inicial}

Durante o exame facial em norma frontal, não é verificada assimetria facial, pois a mandíbula não apresenta desvio ou assimetria (Fig. 25). Em MIH,

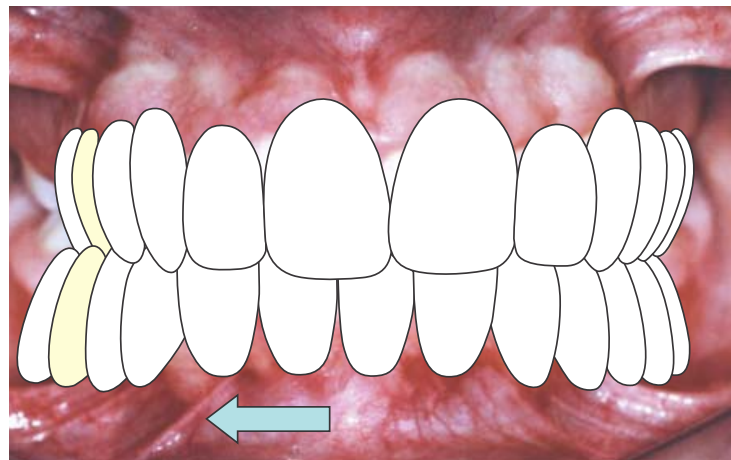

FIGURA 21 - Desvio da linha média inferior devido ao contato prematuro nos dentes em mordida cruzada (MIH).

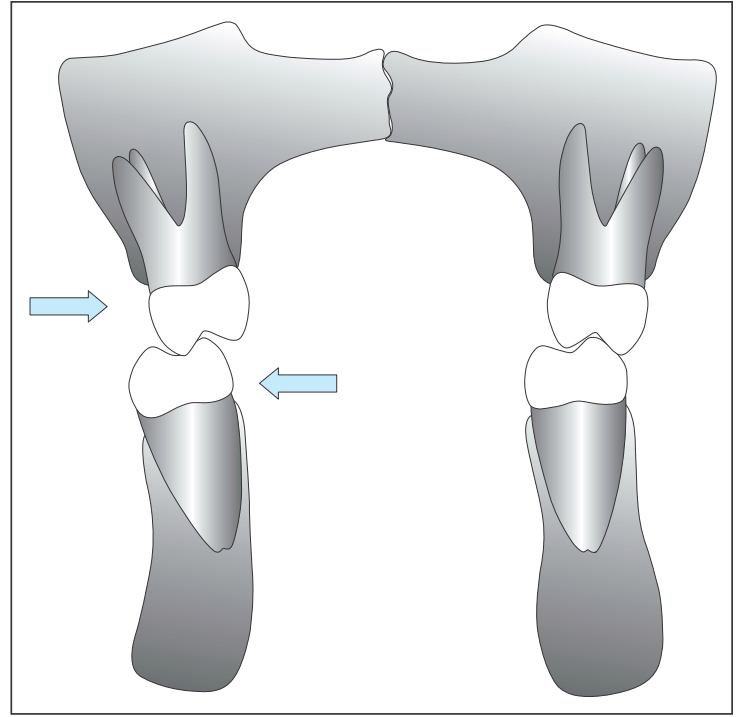

FIGURA 22 - Corte transversal em MIH. Bases ósseas normais e mordida cruzada dentária.

o paciente apresenta um ou dois elementos dentários posteriores com assimetria em relação aos outros dentes e em mordida cruzada com seus antagonistas (Fig. 26). Devido à ausência de contatos prematuros não se observa desvio da linha média inferior. Os arcos dentários apresentam-se normais, não sendo observada nenhuma atresia esquelética dos mesmas.

\section{Diagnóstico definitivo}

Conclui-se que o paciente é portador de uma mordida cruzada posterior dentária sem desvio mandibular quando, em RC, apresenta o mesmo 


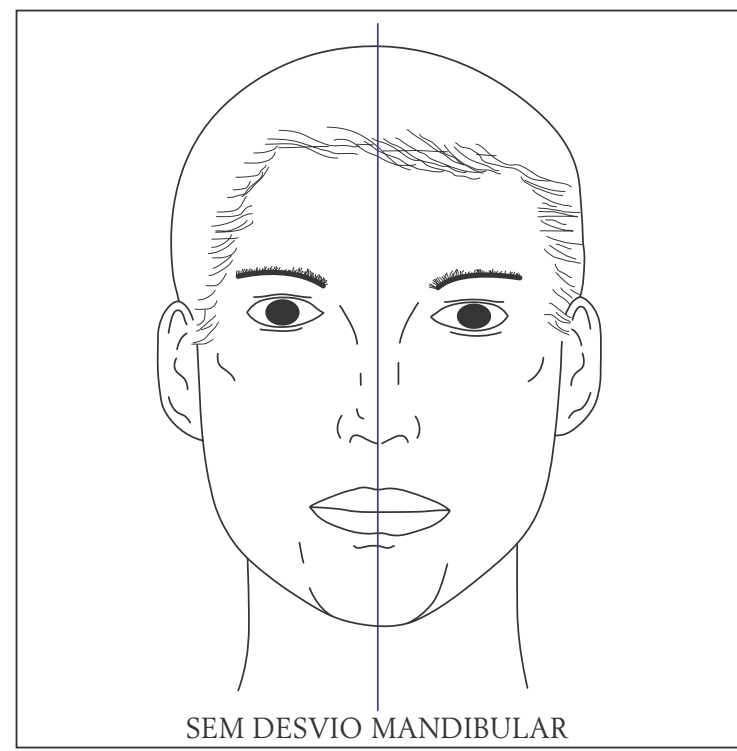

FIGURA 23 - Simetria facial em RC.

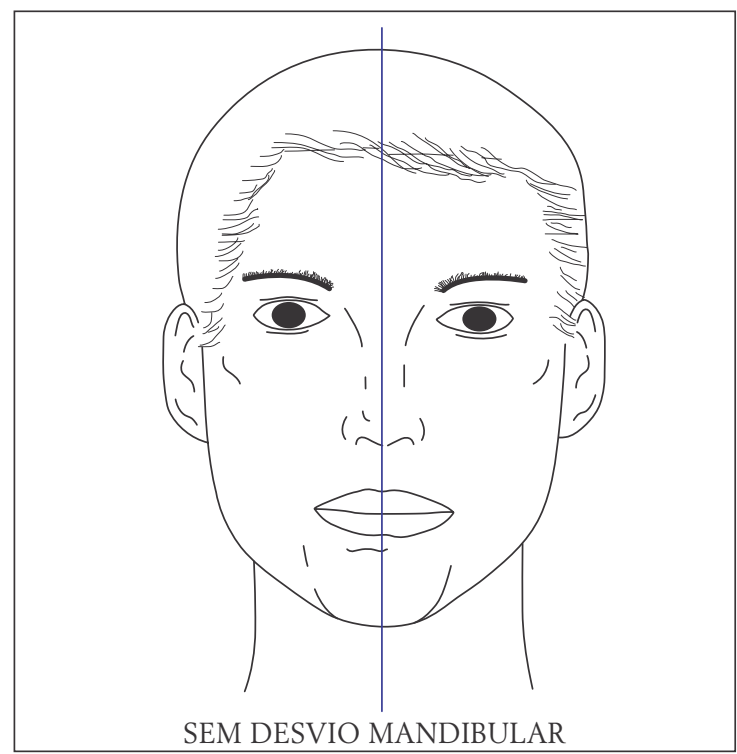

FIGURA 25 - Face simétrica e sem desvios em RC.

padrão oclusal que em MIH, ou seja, presença de apenas um ou dois elementos dentários em mordida cruzada, devido a inclinações dentárias errôneas, sem comprometimento esquelético (Fig. $27,28)$, portanto, indicando a correção destes elementos dentários para suas posições normais, tornando-os simétricos em relação aos outros.

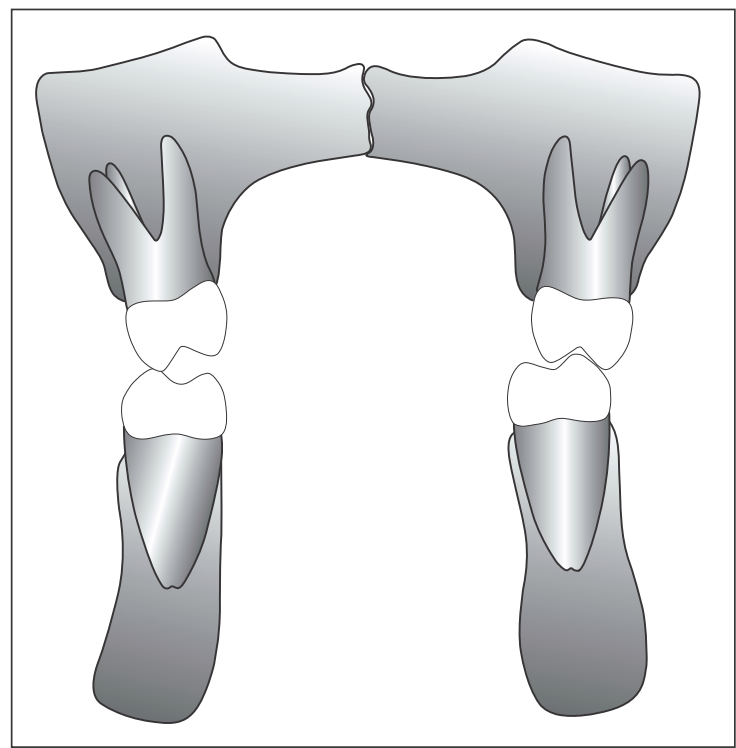

FIGURA 24 - Corte transversal em RC. Bases ósseas normais e prematuridade oclusal devido à inclinação dentária errônea.

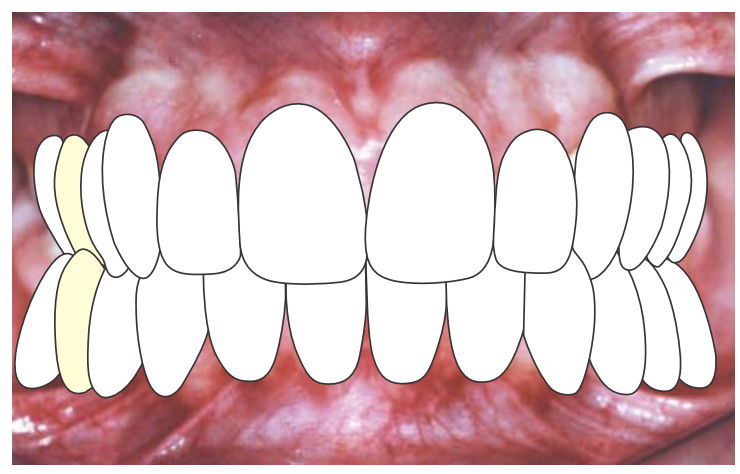

FIGURA 26 - Em MIH, linhas médias coincidentes e mordida cruzada dentária posterior.

\section{MORDIDA CRUZADA POSTERIOR VESTIBULAR TOTAL}

Essa má oclusão, também conhecida como síndrome de Brodie, se caracteriza por uma relação anormal no sentido vestíbulo-lingual entre a maxila e a mandibula, onde a maxila engloba toda a mandíbula, ou seja, em mordida cruzada vestibular total. Esta má oclusão pode resultar de uma maxila excessivamente larga (Fig. 29), de uma atresia severa da mandíbula (Fig. 30) ou ainda uma combinação destas duas situações.

Em MIH observa-se que o arco maxilar está to- 


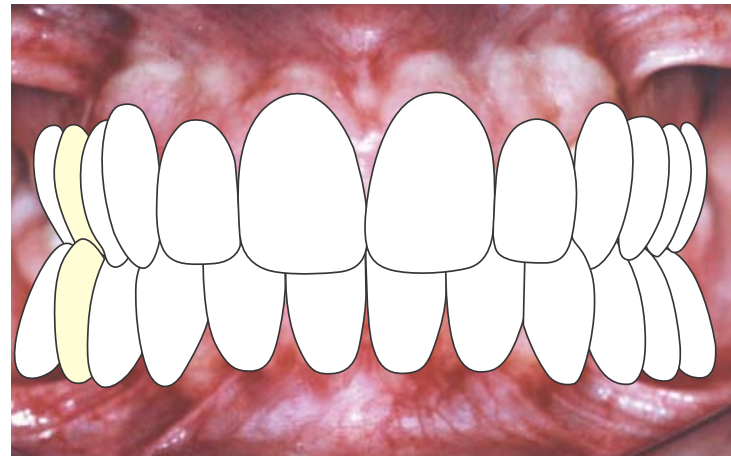

FIGURA 27 - Em RC há coincidência das linhas médias e mordida cruzada em apenas dois dentes.

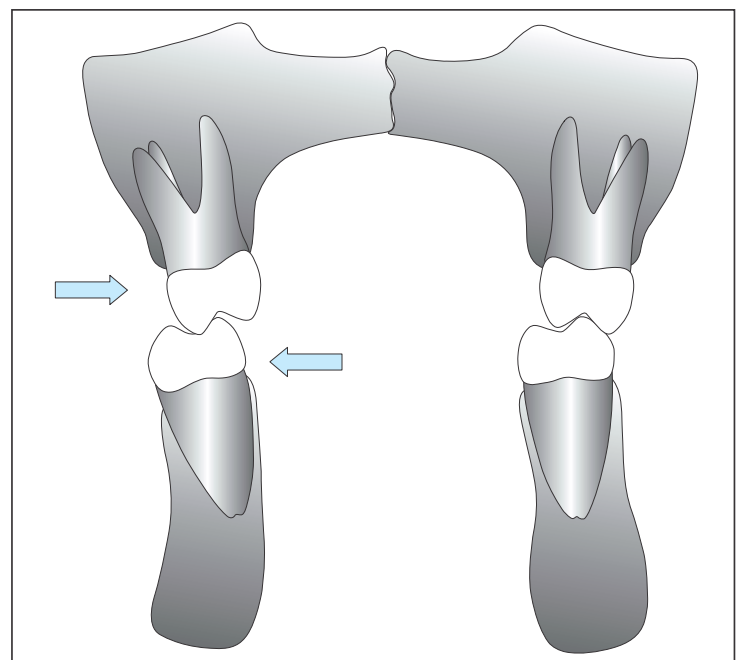

FIGURA 28 - Bases ósseas normais. Mordida cruzada dentária devido a inclinações axiais incorretas (RC).

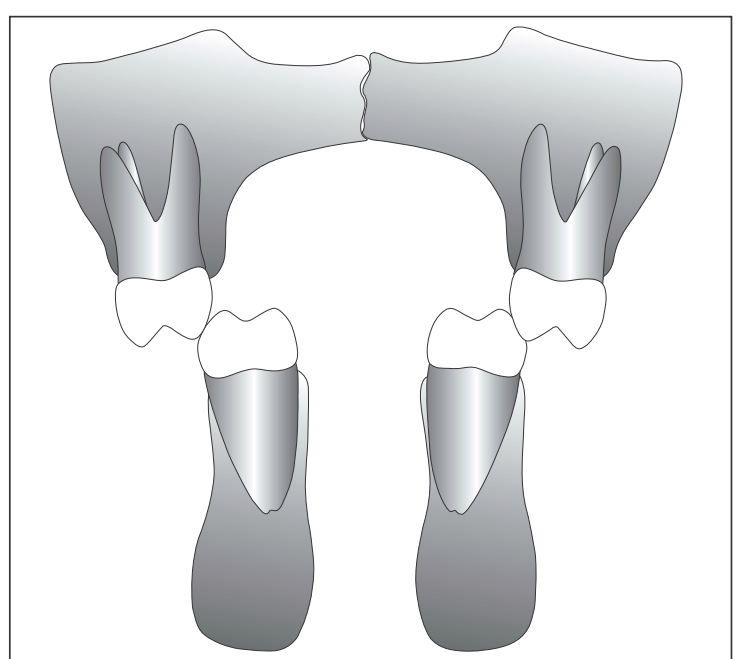

FIGURA 30 - Atresia severa da mandíbula no sentido transversal, gerando uma mordida cruzada vestibular total.

dida cruzada, o caso poderá ser tratado somente ortodonticamente ou com auxílio de cirurgia.

\section{CONSIDERAÇÕES FINAIS}

Esperamos que esta classificação de mordida cruzada posterior apresentada possa conduzir o clínico a um fácil diagnóstico e plano de tratamento mais adequado.

Quanto ao recurso terapêutico a ser utilizado, 
o profissional deverá dispor daquele que melhor se adapte ao problema do paciente, considerando as atresias mais importantes ou menos importantes, que podem ser somente dentárias, dentoalveolares ou nas formas mais graves, esqueléticas.

Quanto à época ideal de tratamento, a mesma deve ser o mais precoce possível, desde o momento em que o paciente aceite o tratamento, para que a correção permita um crescimento adequado sem assimetrias, pois as mesmas poderão se tornar definitivas se a mordida cruzada não for tratada precocemente.

\title{
Posterior crossbite: a more didactic classification
}

\begin{abstract}
The aim of this work is to present a new posterior crossbite classification, being this more didactic and of easy understanding, differing from the others in your nomenclature, preserving, however, the basic principles that govern the Orthodontics. This new classification makes the posterior crossbite diagnosis process systematized and accurate, assisting the clinician in the elaboration of a suitable treatment plan and as consequence, leading to more favorable prognostic of this malocclusion.
\end{abstract}

Key words: Malocclusion. Posterior crossbite. Classification.

\section{REFERÊNCIAS}

1. ARAÚJO, M. C. M. Mordida cruzada. In:__. Ortodontia para clínicos. 2. ed. São Paulo: Ed. Santos, 1982. p. 233-243.

2. BELL, R. A. LECOMPTE, E. J. The effects of maxilary expansion using a quad-helix appliance during the deciduous and mixed dentitions. Am. J. Orthod., St. Louis, v. 79, no. 2, p. 152-161, 1982.

3. BUCK, D. L. The fixed $W$ arch for correction of posterior crossbites in children. J. Am. Dent. Assoc., Chicago, v. 81, p. $1440-1442,1970$

4. CELENZA, F. V. The theory and clinical management of centric positions: I| centric relation and centric relation occlusion. Int. J. Period. Restorat. Dent., Hanover, v. 4, no. 6, p. 63-86, 1984.

5. COHEN, M. M. Ortodontia pediátrica preventiva. Rio de Janeiro: Interamericana, 1979

6. FOSTER, T. D. HAMILTON, M. C. Occlusion in the primary dentition: study of children at $21 / 2$ to 3 years of age. Br. Dent. J., London, v. 126, no. 2, p. 76-79, 1969.

7. GRABER, T. M. Orthodontics: principles and practice. 3rd. ed. Philadelphia: W. B. Saunders, 1972.

8. HANSON, M. L.; BARNARD, L. W.; CASE, J. L. Tongue-thrust in preschool children. Part II: dental occlusion patterns. Am. J. Orthod., St. Louis, v. 57, no. 1, p. 15-22, 1970.

9. HANNUKSELA, A.; VAANANEN, A. Predisposing factors for malocclusion in 7-year-old children with special reference to a topic diseases. Am. J. Orthod. Dentofacial Orthop., St. Louis, v. 92, no. 4, p. 299-303, 1987.

10. HIGHLEY, L. B. Crossbite: mandibular malposition. J. Dent. Child., Chicago, v. 35, no. 3, p. 221-223, 1968.
11. INFANTE, P. F. Malocclusion in the deciduous dentition in white black and apache indian children. Angle Orthod., Appleton, v. 45 , no. 3, p. 213-218, 1975.

12. JARVINEN, S. Need of preventive and interceptive intervation for malocclusion in 3-5 year-old finish children. Comunity Dent. Oral. Epidemiol., Copenhagen, v. 9, no. 1, p. 1-4, 1981.

13. KANTOMAA, T. Correction of unilateral crossbite in the deciduous dentition. Eur. J. Orthod., Oxford, v. 8, p. 80-83, 1986.

14. KISLING, E. Occlusal interferences in primary dentition. J. Dent. Child., Chicago, v. 48, no. 3, p. 181-191, 1981.

15. KUTTIN, G.; HAWES, R. R. Posterior crossbite in deciduous and mixed dentition. Am. J Orthod., St. Louis, v. 56, n. 5, p. 491-504, 1969.

16. LEIGHTON, B. C. The early development of crossbites. Dent. Pract., Cincinnati, v. 17, n. 4, p. 145-152, 1966.

17. McDONALD, R. E.; AVERY, D. R. Diagnóstico e correção de pequenas irregularidades na dentição em desenvolvimento. In: Odontopediatria. 4. ed. Rio de Janeiro: Guanabara Koogan, 1986. p. 470-472.

18. MODESTO, A. et al. Estudo da prevalência da mordida cruzada posterior. Rev. Odondol. Bras., Rio de Janeiro, v. 51, n. 1, p. 2-4, 1994.

19. MOYERS, R. E. Classificação e terminologia da má-oclusão. In: Ortodontia. 4. ed. Rio de Janeiro: Guanabara Koogan, 1991. p. 156-157

20. MYERS, D. R. et al. Condilar position in children with functional posterior crossbites: before and after correction. Pediat. Dent. Chicago, v. 2, p. 190-195, 1980. 
21. PETERS, C. F. GAVAZZI, J. C. C.: OLIVEIRA, S. F. Estudo da prevalência de mordidas cruzadas na dentadura decídua. Relação com hábitos de sucção. Rev. Paul. Odontol., São Paulo, . 8, n. 2, p. 38-43, 1986

22. PROFFIT, W. R. et al. Diagnóstico ortodôntico: desenvolvimento de uma lista de problemas. In __. Ortodontia contemporânea. 3. ed. São Paulo: Pancast, 1991. p. 133-207.

23. SILVA FILHO, O. G. Alterações cefalométricas ocorridas na dentadura mista após o uso de um expansor fixo tipo quadrihélice. Ortodontia, São Paulo, v. 19, p. 22-33, 1986.

24. SILVA FILHO, O. G. Avaliação das alterações dentárias e esqueléticas ocorridas na dentadura mista, após o uso do expansor fixo tipo quadri-hélice. Ortodontia, São Paulo, v. 18, p. 23-35, 1985.
25. ANDO,$T$. Fatores pós-natais intríncecos de interesse para Ortodontia Preventiva. In: GUEDES-PINTO, A. C. Odontopediatria. 2. ed. São Paulo: Ed. Santos, 1990. p. 897-998.

26. VIGORITO, J. W. Mordidas cruzadas: descruzadores de mordida. In: Ortodontia clínica preventiva. 2. ed. São Paulo: Artes Médicas, 1986. p. 169-205.

27. WOOD, A. Anterior and posterior crossbites. J. Dent. Child. Chicago v. 29 , p. 280-286, 1962

28. WRIGHT, C. F. Crossbites and their management. Angle Orthod., Appleton, v. 23, p. 35-45, 1953
Endereço para correspondência

Arno Locks

Rua Presidente Coutinho, 311 Conj. 1101

CEP: 88.015-230 - Centro - Florianópolis / SC

E-mail: arnoorto@terra.com.br 